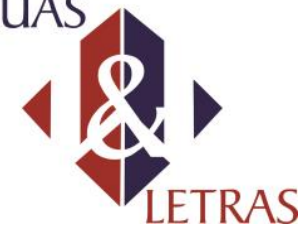

\title{
Um Olhar Afro-Brasileiro para 0 Cortiço
}

\author{
An afro-brazilian look for $o$ Cortiço \\ Carlos Magno Santos Gomes* \\ Deise Santos do Nascimento** \\ * Universidade Federal de Sergipe, Curso de Letras - campus de Itabaina. Av. Vereador \\ Olímpio Grande S/N - Bloco C - 49000-000 - Itabaiana, SE - Brasil, e-mail: \\ calmag@bol.com.br \\ ** Universidade Federal de Sergipe, Curso de Letras - campus de Itabaina. Av. Vereador \\ Olímpio Grande S/N - Bloco C - 49000-000 - Itabaiana, SE - Brasil
}

RESUMO: Este artigo faz uma releitura do romance $O$ cortiço, de Aluísio Azevedo, a partir das reflexões teóricas sobre os conceitos que envolvem a literatura afro-brasileira. Nessa obra, a representação da mulher negra nos remete aos estereótipos de raça e de gênero: a mulher sedutora, responsável pelos descaminhos do homem branco. Metodologicamente, aproximamos a categoria "literatura negra", de Zilá Bernd (1987), da proposta engajada de "literatura afrobrasileira", de Eduardo de Assis Duarte (2011), para debatermos sobre as possibilidades de revisão do passado colonial brasileiro nos textos literários. Para tanto, utilizamos uma abordagem de leitura do texto literário que valoriza os intertextos culturais das representações artísticas. Conforme os estudos comparados, o diálogo entre textos e cultura promove a releitura crítica do passado, pois o texto literário passa a ser iluminado por um olhar pós-colonial.

PALAVRAS-CHAVE: Questões étnico-raciais; Pós-colonialismo; Literatura afro-brasileira.

ABSTRACT: This article is a re-reading of the novel $O$ cortiço, by Aluísio Azevedo, from theoretical reflections about the concepts that involve AfroBrazilian literature. In that work, the representation of black woman takes us to the stereotypes of race and gender: seductive woman, responsible for the white man misguided. Methodologically, we get the category "black literature", by Zilá Bernd (1987), closer to the engaged proposal of "Afro-Brazilian literature", by Eduardo de Assis Duarte (2011), to discuss about the possibilities for revision of the Brazilian colonial past in the literary texts. Therefore, we used an approach of literary text reading that emphasizes the cultural intertexts of the artistic representations. According to the comparative studies, the dialogue between texts and culture promotes the critical rereading of the past, because the literary text becomes illuminated by a post-colonial look.

KEYWORDS: Ethnic-racial questions; Post-colonialism; Afro-Brazilian literature. 
Este artigo apresenta uma abordagem pós-colonial para analisarmos os textos literários que trazem representações afro-brasileiras. No primeiro momento, debateremos sobre estratégias de interpretações das questões étnico-raciais a partir das especificidades ideológicas e políticas quem envolvem essa temática. No segundo, apresentamos um recorte de revisão do lugar da mulher negra no romance $O$ Cortiço, de Aluísio Azevedo. Nossa meta é questionar os sentidos dessa representação, nesse clássico realista, com a finalidade de atualizar seus sentidos dentro da história literária brasileira.

Como esta proposta, questionamos os estereótipos raciais que circulam na cultura brasileira a partir da ampliação dos sentidos das representações literárias. Essa obra foi escolhida como parâmetro interpretativo por apresentar duas personagens representativas dos estereótipos da mulher negra na história da literatura: Rita Baiana, a mulata sensual; e Bertoleza, a negra trabalhadora. As duas trazem as marcas dos abusos moral e físico impostos às afro-brasileiras.

Antes de detalharmos como esses abusos acontecem, discutiremos parâmetros pós-coloniais que revisam tais representações. Na sequência, apresentamos estratégias metodológicas pautadas nas contribuições de Stuart Hall (2003), Homi Bhabha (1998) e Edward Said (1995). No caso brasileiro, diferenciamos as abordagens acerca da "literatura negra", proposta por Bernd (1987), e da "afro-brasileira", defendida por Eduardo Duarte (2011).

\section{UMA ABORDAGEM PÓS-COLONIAL}

O processo de ressignificação faz parte das estratégias de revisão cultural das desigualdades raciais, quando escolhemos os parâmetros pós-coloniais. Para isso, levamos em conta o fato de que, no "processo contínuo de significação do mundo cultural e ideológico", a ressignificação é um processo sem fim (HALL, 2003, p. 362). Para isso, devemos estar abertos a entender as diferenças culturais e ideológicas entre a visão do colonizador e as identidades afro-brasileiras, pois a diferença cultural "é um processo de significação através do qual afirmações da cultura ou sobre a cultura diferenciam, discriminam e autorizam a produção de campos de força, referência, aplicabilidade e capacidade" (BHABHA, 1998, p. 63). 
Tal processo de releitura tenta identificar a camada ideológica das representações coloniais, visto que “"o quê' e o 'como' nas representações das 'coisas', mesmo admitindo uma considerável liberdade individual, são circunscritos e socialmente regulados" (SAID, 1995, p. 120). Esse processo de revisão é parte da recepção crítica dos textos literários. No ato de abordar uma representação social, marcada pelo preconceito e opressão, como o caso do corpo da mulher negra, devemos identificar como os problemas históricos foram representados artisticamente.

Quanto às questões étnico-raciais, optamos por abandonar a posição passiva de interpretação dos sentidos das personagens negras no romance de Aluísio Azevedo. Em contrapartida, incorporamos uma posição inquietante e revisionista que reconhece o ato de ler como uma prática de experiência e aquisição de poder (BHABHA, 1998, p. 23).

Tal posição faz parte da agenda crítica que dá sustentação a lei 10.639/03, que nos convida a pensar sobre a história da cultura afro-brasileira e africana na Educação. Com mais de uma década dessa lei, pouco avançamos nas estratégias de leitura que desconstruam a visão do colonizador. Na maioria das vezes, a personagem negro/a é posto/a como coadjuvantes dos acontecimentos. Para romper com esse olhar homogêneo, reforçamos a prática de interpretação de textos literários que valorize a ressignificação das representações, como nos propõe Stuart Hall (2003, p. 362).

A postura revisionista, adotada neste artigo, permite a diferenciação entre as obras que repetem o olhar do colonizador em oposição às que trazem as representações afrobrasileiras engajadas. Nessa direção, devemos deixar de lado o lugar cômodo da recepção passiva para propor uma crítica acerca das interpretações vinculadas ao sistema patriarcal misógino e racial. Com isso, provocamos reflexões sobre o passado e o presente dos afro-brasileiros, pois “mesmo depois da Abolição, a cor escura continuou em muitas instâncias da vida social brasileira a ser encarada como "defeito"” (DUARTE, 2011, p. 16).

Damos sequência a esse debate, perguntando sobre quais os textos devemos incluir em nossas práticas de leitura crítica sobre questões étnico-raciais? As obras canônicas de autores brancos, ou as propostas de autores afro-brasileiros que trazem sua autoafirmação identitária? Diante da diversidade artística brasileira e de nossas formações culturais diferentes, sabemos que não há uma resposta pronta, já que há muitos caminhos válidos para se revisar o passado.

Como resposta preliminar, defendemos o "modelo cultural de leitura", isto é, uma prática de leitura que explora os textos históricos como iluminadores do processo 
interpretativo. Quando pensamos em avançar no processo de revisão do lugar do afrobrasileiro, reforçamos as diferenças entre identidade e alteridade como parte do processo de leitura, visto que "o modelo cultural de leitura parte do questionamento da identidade hegemônica para incluir a alteridade como parte da leitura" (GOMES, 2012, p. 171). Sabemos que há outras tensões relevantes, mas, por enquanto, passemos para uma reflexão sobre a importância da revisão do olhar do colonizador em nossas práticas de leitura.

O processo de revisão da história literária é uma das etapas de valorização da identidade afro-brasileira. O que se pretende aqui é deslocar a visão do colonizador e, com isso, proporcionar o questionamento de marcas pejorativas formadas ao longo da história do país. Segundo Duarte (2014), é a partir da década de 70, do século XX, que os escritores negros reúnem-se para construir um espaço literário organizado em combater o racismo e afirmar os valores, excluídos, de caráter cultural e histórico. Por parte de iniciativas como essa, que se identifica o lugar para uma Literatura feita por afrodescendentes brasileiros; ação oportuna para verdadeiramente desmistificar o que por muito tempo, de maneira equivocada, vem se falando sobre a imagem do negro.

Para esse tipo de leitura que prioriza a questão de "como" os elementos culturais estão representados, o texto necessita de uma interpretação dos significantes que relacione o texto lido a suas heranças culturais. A cultura é uma forma de representação e produção dos ícones e símbolos por meio dos quais o homem vive sua própria cultura. Tais heranças são fundamentais para uma perspectiva comparativa entre o texto lido e o passado cultural, já que "cada obra cultural é a visão de um momento, e devemos justapor essa visão às várias revisões que ela gerou" (SAID, 1995, p. 105).

\section{O LUGAR DO AFRO-BRASILEIRO NA LITERATURA}

Entre os conceitos étnico-raciais, desenvolvidos para analisarmos os textos literários, vamos nos restringir a duas termologias: "literatura negra", de Zilá Bernd (1987), e "literatura afro-brasileira", de Eduardo de Assis Duarte (2014). Esses conceitos diferenciam os textos que representam o negro pelo olhar do colonizador daqueles que trazem a voz engajada do afro-brasileiro como sujeito que luta por causa e direito de igualdade. 
Historicamente, identificamos nas obras literárias a permanência de uma descrição ideologicamente marcada pelo olhar do colonizador. Em grande parte dos textos escolares, o negro é descrito como subalterno, marginalizado, ou excluído como, por exemplo, as obras regionalistas, de José Lins do Rêgo e Jorge de Lima: o romance Menino de engenho e o poema "Essa negra Fulô", respectivamente. Tais clássicos repetem o olhar do colonizador. Isso fica mais visível quando pensamos nos estereótipos do negro e da negra que ultrapassam gerações. Na verdade, por conta do processo de colonização do Brasil, isso é identificado em virtude de imagens impostas por meio dos mandos e desmandos da classe dominante.

Diante desses impasses, construídos pelo processo de colonização, retornamos o debate sobre as abordagens das representações afro-brasileiras na história literária como estratégia de revisão cultural. Acerca da problemática das diferentes formas de se estudar tais representações, o pesquisador Eduardo Duarte considera que nem sempre há espaço para a voz do negro/a, por ela "falar de sua condição de escravizado, ou de homem livre na sociedade escravocrata, levantar sua voz contra a barbárie do cativeiro; ou já no século XX, enquanto sujeito dolorosamente integrado ao regime do trabalho assalariado; ou excluído e submetido às amarras do preconceito, com suas mordaças" (2011, p. 5).

Nos textos canônicos, a figura do negro e sua cultura giram, quase sempre, em torno de questões marginalizadas e/ou pejorativas que tendem a repetir o senso comum. Contudo, na literatura, em especial a canônica, encontra-se "o negro não só como raro tema da escrita do branco, mas com voz/vozes voltadas para a expressão de seu ser e existir" (DUARTE, 2011, p. 05). Isso nos possibilita perceber que, mesmo mediado por uma ação do contexto do colonizador, há a oportunidade de se tratar dessa temática de forma revisionista nos textos clássicos.

Nesse debate, torna-se interessante identificar e ampliar o conceito acerca de afrodescendência, que vai além da construção de identidades e passa pela reflexão acerca dos elementos das culturas africana e afro-brasileira, que faz parte da identidade Nacional. Como estratégia de leitura, propomos a valorização das questões ideológicas para desconstruirmos as interpretações historicamente tratadas pelo olhar do colonizador para retomá-las “dentro de um referencial alternativo" (HALL, 2003, p. 402).

Historicamente, podemos identificar diferentes escritores preocupados com as questões étnico-raciais, todavia nem todos dão voz ao negro/a, visto que preferem 
valorizar o olhar do colonizador. Um dos principais estereótipos dessa tradição está na construção da imagem da mulata como signo de sexualidade. Por exemplo, de Gregório de Matos a Jorge Amado, a mulata é representada como um objeto sexual estéril e quase sempre "reduzida a signo cujo sentido permanece prisioneiro de um discurso em que racismo e sexismo se emparelham" (DUARTE, 2010, p. 25). Já Memórias de um sargento de milícias, de Manoel Antônio de Almeida, temos uma representação animalesca dessa sexualidade.

Dentro desse debate teórico, Zilá Bernd considera haver no Brasil uma "Literatura Negra" que se opõe a um ato literário que traz apenas a temática do negro. Para ela, aquela literatura é reconhecida como tal por trazer um "eu enunciador que se quer ser negro, que reivindica a sua especificidade negra" (1987, p. 16). A partir dessa concepção, podemos considerar que a "Literatura Negra" tanto pode ser produzida por autores brancos, negros ou afrodescendentes, visto que basta esses textos trazerem "um modo negro" de se ver o mundo. Logo, quando os escritores, por meio de fatores históricos denotam em seus textos essa consciência, há ali, então, uma voz enunciadora do pertencimento à cultura afro, um discurso de identidade.

Contrário a essa concepção, Eduardo Duarte amplia o debate e propõe restrições aos textos que podem fazer parte da "literatura afro-brasileira", considerando que o seu reconhecimento deve perpassar por quatro aspectos: Temática que compreende a incorporação da experiência da figura do negro ao texto literário; Autoria, o negro é o sujeito de sua enunciação, colocando sua maneira de ver, sentir e entender o mundo; Ponto de vista em que se perceber a relação e influência da história e tradição negras e, por fim a Linguagem que está baseada em um discurso específico, apresentado por marcas que remetem a heranças de aspecto linguístico e da cultura africana (DUARTE, 2015, p. 11).

Portanto, uma "literatura afro-brasileira" é feita por um "escritor negro brasileiro". Segundo Duarte, o termo afro agrega maior valor para conduzir a discussão do tema, por possuir mais propriedade, seja no aspecto da ficção, como na poesia. Sobre essa questão, o pesquisador ainda faz considerações acerca do modo peculiar da linguagem colaborar para a divulgação da referida cultura e pontua que, "a configuração dessa diferença passa pelo trabalho com a linguagem, a fim de subverter imagens e sentidos cristalizados. É uma escrita que, de formas distintas, busca dizer-se negra, até para afirmar o antes negado" (DUARTE, 2015, p. 11). 
Portanto, ponderando o dito aqui, ressaltamos as contribuições dos dois pesquisadores, visto que questionam o perfil do colonizador, seja com o olhar canônico da "literatura negra", seja com a ampliação política do termo "literatura afro-brasileira", produzidas por autoras e autores negros, de diferentes contextos históricos, como Lima Barreto, Carolina de Jesus e Conceição Evaristo. Esses dois conceitos nos convidam a repensarmos nossas estratégias de leitura do imaginário cultural afro-brasileiro. $\mathrm{Na}$ sequência, revisamos o olhar do colonizador nas representações da mulher em $O$ cortiço, de Aluísio Azevedo.

\section{DA MULATA À TRABALHADORA}

Para uma prática crítica, recomendamos o uso da intertextualidade como uma ferramenta indispensável para a ampliação dos sentidos de um texto. Tanto a referência a outros textos literários, como também aos arquivos históricos, pode nos auxiliar a desvendarmos os sentidos de uma obra. Esse processo comparativo que leva em conta os elementos da história é fundamental para evitarmos o senso comum, visto que em um processo crítico, "precisamos sempre comparar o texto lido com outros conhecimentos que trazemos para o processo de interpretação" (GOMES, 2014, p. 106).

Tal processo de leitura explora os conceitos de intertextualidade cultural que amplia o horizonte de expectativa de um texto por meio da rede de conexões sociais e artísticas que cada texto carrega. Tal "modelo de leitura cultural" reconhece o poder de uma identidade rasurar outra, visto que as identidades "étnico-raciais não podem ser lidas sem os conflitos raciais impostos pelo colonizador" (GOMES, 2012, p. 172).

Nesse processo de construção dos sentidos textuais, devemos ser capazes de decodificar os sentidos estéticos do texto, uma vez que a construção de sentidos requer "atualização" e "movimentos cooperativos, conscientes e ativos da parte do leitor" (ECO, 2004, p. 36). Tal atualização dos sentidos do texto literário está relacionada ao processo de revisão do passado cultural. Esse passado é narrado por um olhar colonizador que deixou rastros da dominação e opressão. Assim, preencher os "espaços vazios" do texto é reconhecer que o contexto histórico deve ser trazido para o processo de leitura. (ECO, 2005, p. 46)

Ao preencher os espaços étnico-raciais da obra $O$ Cortiço, de Aluísio Azevedo, com uma visão que desloca o olhar do colonizador, propomos revisar o lugar do afro- 
brasileiro na história literária. Nesse romance, verificamos que o escritor abolicionista Aluísio de Azevedo utiliza determinados estereótipos da raça negra próprios de sua época e comuns à estética Naturalista.

Em tal contexto, prevalecia a visão preconceituosa e racista do colonizador. Por isso, ao longo dessa narrativa é fácil percebermos algumas representações de homens e mulheres negros que ainda são identificados no contexto atual: a mulher negra escravizada, ou a mulata exótica e sedutora, da "cor do pecado" para o homem branco.

Para esta análise, vamos no deter na releitura da imagem mulata, estereótipo sexualizada, vista como objeto sexual do colonizador; e da escrava, a que trabalhou para a construção do Brasil, mas é traída na hora da divisão dos bens entre brancos e negros. Esses dois estereótipos serão analisados por meio de uma perspectiva pós-colonial das personagens Rita Baiana e Bertoleza, respectivamente. No primeiro momento, abrimos espaço para a mulher erotizada, símbolo da sensualidade nacional, Rita Baiana:

Ela saltou em meio da roda, com os braços na cintura, rebolando as ilhargas e bamboleando a cabeça, ora para a esquerda, ora para a direita, como numa sofreguidão de gozo carnal, num requebrado luxurioso que a punha ofegante já correndo de barriga empinada; já recuando de braços estendidos, a tremer toda, como se se fosse afundando num prazer grosso que nem azeite, em que se não toma pé e nunca se encontra fundo (...) (AZEVEDO,1984, p. 72-3).

Além da sensualidade, em volta dessa mulata, temos diversos elementos culturais que marcam a identidade brasileira, pois essa obra também tem a intenção de divulgar os costumes populares da cultura negra. Rita Baiana é guardiã de tal responsabilidade, e seu gosto pela música (tratada pelo seu namorado Firmo), pela dança, pela comida e pela bebida (o café e o parati), são marcas de um novo gosto que forma a identidade nacional. Essas peculiaridades identitárias são vistas como pontos positivos de nossa cultura e dignas de apreciação e respeito pelo colonizador. A força erótica dessa mulher trasborda pelas páginas do romance "ela era a luz ardente do meio-dia; ela era o calor vermelho das sestas da fazenda; era o aroma quente dos trevos e das baunilhas, que o atordoara nas matas brasileiras" (AZEVEDO, 1984, p. 76).

Por ter sido escrita por um homem branco, retomamos a reflexão em torno da forma como essa representação está articulada. Como visto anteriormente, a "literatura negra" está voltada para descreve a tradição dos valores e da cultura afro-brasileira conforme Zilá (1987). Todavia, o romance de Azevedo não tem esse objetivo no todo. Apenas nessas cenas de composição da identidade nacional, temos registrado o exótico e a sensualidade como a contribuição afro-brasileira.

Volume 17

Número 38 


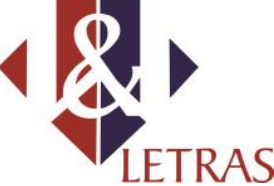

Vale destacar que, ao chamar a atenção para a forma como as festas e a culinária de origem africana contribuíram para a construção dessa identidade, esse romance repete a visão da época, pois está associada à preguiça e ao espirito festeiro do brasileiro: "E assim ia correndo o domingo no cortiço até às três, horas em que chegou mestre Firmo, acompanhado pelo seu amigo Porfiro, trazendo aquele o violão e o outro o cavaquinho [...]. E não tardou que se ouvissem gemer o cavaquinho e o violão (AZEVEDO, 1984, p. 66-67). Tal concepção cultural reconhece a grande contribuição das musicalidade africana para a música brasileira, mas, naquele espaço é vista como algo negativo, como próprio do negro preguiçoso irresponsável e está associada à imagem de bêbedos e brigões como Firmo e seus amigos.

Quanto aos movimentos de Rita Baiana, o texto de Azevedo os vincula ao erotismo. Essa personagem é descrita como sendo detentora de inúmeras qualidades sedutoras: livre, bela, asseada, perfumada, alegre, independente. Além disso, traz a solidária como marca de sua identidade. Ela é querida por todos do cortiço por ter bons sentimentos. Todavia, é valorizada seu espírito festeiro, sabendo cantar e dançar de forma exuberante. Por ser dona da naturalidade baiana, a ela é conferido o status da mulher sensual e rebelde. Ela traz a marca da liberdade e não aceita e seguir regras:

Rita havia parado em meio do pátio.

Cercavam-na homens, mulheres e crianças; todos queriam novas dela. Não vinha em traje de domingo; trazia casaquinho branco, uma saia que lhe deixava ver o pé sem meia num chinelo de polimento com enfeites de marroquim de diversas cores. No seu farto cabelo, crespo e reluzente, puxado sobre a nuca, havia um molho de manjericão e um pedaço de baunilha espetado por um gancho. E toda ela respirava $\mathrm{o}$ asseio das brasileiras e um odor sensual de trevos e plantas aromáticas. Irrequieta, saracoteando o atrevido e rijo quadril baiano, respondia para a direita e para a esquerda, pondo à mostra um fio de dentes claros e brilhantes que enriqueciam a sua fisionomia com um realce fascinador (AZEVEDO, 1984. p. 65-68).

A sensualidade de Rita é uma construção do colonizador que foi aceita pela história oficial. O poder de sedução do seu corpo é marcado pela independência da mulher livre, que pode ser objeto sexual dos vários homens a sua volta. Sobre essa questão, chega-se à conclusão de que a visão atribuída hoje à mulher afrodescendente traz resquícios dessa construção do colonizador.

Para romper com esse prisma, devemos nos armar de duas estratégias: a primeira alargar os sentidos do texto por meio de uma recepção ativa, visto que "o texto não apenas repousa numa competência, mas contribui para produzi-la" (ECO, 2004, p. 40); 


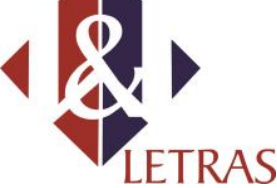

a segunda deve ser fortalecida pelo objetivo de revisão como nos orienta Hall (2003), romper com o padrão imposto pela “comunidade interpretativa". Nesse caso do colonizador.

Assim, podemos dizer que o texto de Aluísio de Azevedo apresenta "espaços abertos”, para que o leitor crítico atualize sua concepção, questionando a imagem da mulher objeto com a qual a afro-brasileira é cantada nos textos artísticos. Essa representação coisificada da mulher negra e da mulher mulata surge em oposição às mulheres que poderiam se casar, visto que "a personagem feminina oriunda da diáspora africana no Brasil tem lugar garantido, em especial, no que toca à representação estereotipada que une sensualidade e desrepressão: 'Branca para casar, preta para trabalhar e a mulata para fornicar"” (DUARTE, 2010, p. 24).

Ainda no romance de Azevedo, essa questão fica exposta quando Rita Baiana é descrita como oposta da mulher para o casamento. Esse discurso do colonizador se apresenta na obra de diferentes formas. A sensualidade de Rita é capaz de destruir um casamento. Essa metáfora fica mais marcante na obra de Azevedo, quando associada ao desejo do europeu, Jerônimo. Para esse português, a mulata brasileira "sabe tratar um homem como deve ser", em detrimento de sua esposa portuguesa, que fica limitada a cuidar do lar e ser a acolhedora da família, afinal ela é branca.

É interessante colocar, também, que essa visão sexualizada da mulher negra não é nenhuma novidade ao texto de Azevedo e foi retomada durante o século XX. Tal questão fica exposta quando é atribuído às personagens negras: o sinônimo de corpo disponível. Essa recorrência silencia a identidade materna e protetora das mães negras, que também têm desejo de formação de uma família. Segundo Duarte, "a mulata construída pela literatura brasileira tem sua configuração marcada pelo signo da mulher fornicaria da tradição europeia, ser noturno e carnal, avatar da meretriz" (DUARTE, 2010, p. 24).

Nesse processo de revisão, precisamos explorar a coisificação desse corpo feminino a serviço de uma cultura patriarcal. No imaginário cultural e literário, cabe à mulata ficar a serviço do prazer do homem branco, europeu. Esse intertexto histórico é indispensável para o processo de revisão literária, visto que "o uso do intertexto cultural pede um processo de recepção ativa para além do texto literário, pois convida o leitor a propor novos sentidos para os signos textuais através da atualização dos códigos literários" (GOMES, 2014, p. 108). 
Portanto, o processo de revisão deve ser atrelado a uma consciência crítica acerca da desigualdade de gênero e de raça que perpassa a representação de Rita Baiana. Ela é explorada por ser mulher e por ser negra, um duplo lugar de submissão, que no texto de Azevedo é cantado como uma forma de liberdade. Contudo, na ficção, Rita é vista como fora dos padrões patriarcais. Para algumas mulheres brancas, como Piedade, a esposa de Jerônimo, a mulata é vista como uma pessoa imoral, infiel, irresponsável, preguiçosa, de comportamento malicioso e pervertido, dominado pelo desejo e estímulos sensoriais. Esse olhar patriarcal é outra forma de desclassificar a mulher negra nos textos literários.

Essa dupla exclusão feminina é repetida em outras personagens da obra. As criadas de Miranda: Isaura e Leonor são descritas como trabalhadoras e honestas "diferentes" das mulheres festeiras. A criada Isaura é uma mulata, mas é vista como tola; já a negra Leonor é "lisa e seca", e conhece a vasta "tecnologia da obscenidade". Além dessas, as personagens Marciana e sua filha, Florinda, são cobiçadas pelos homens do contexto familiar. No caso da filha, há o atrativo a mais: sua virgindade.

Como destaca Eduardo Duarte, a mulher negra é coisificada nessas narrativas, que silenciam seus desejos por liberdade e cidadania. Ela é apenas um objeto de desejo do colonizador. Tal imagem entre a fronteira da fornicação e do meretrício é mantido por diferentes discursos de valorização da sensualidade do corpo da mulher negra (DUARTE, 2010, p. 24).

O romance de Azevedo nos abre a possibilidade de revisarmos esse estereótipo com a construção crítica de um olhar afro-brasileiro. Além disso, $O$ cortiço descreve uma das metáforas marcante da construção da nacionalidade: a traição do homem branco, quando abandona o povo negro à própria sorte. Essa metáfora pode ser identificada mais precisamente na representação de Bertoleza, explorada para enriquecer o homem branco, mas é abandona por ele, quando pensa em se casar com uma mulher branca.

$\mathrm{Na}$ representação ficcional, Bertoleza não aceita ser jogada na masmorra da escravidão depois de trabalhar tanto. Submissa ao seu companheiro, João Romão, ela é responsável por seu crescimento econômico: "O vendeiro nunca tivera tanta mobília" (AZEVEDO, 1984, p. 25). Todavia, ao perceber que é rejeitada e que não teve sua alforria comprada, Bertoleza não aceita o destino histórico e argumenta: "Sou negra, sim, mas tenho sentimentos! [...] Quero desfrutar o que nós dois ganhamos juntos! Quero a minha parte no que fizemos com o nosso trabalho! Quero o meu regalo, como você quer o seu! [...]" (AZEVEDO, 1984, p. 197). 
Esse grito de Bertoleza é um dos indícios mais importantes para apontarmos o quanto o olhar do colonizador se cristalizou na literatura brasileira a partir de estratégias do silenciamento do/a negro/a. Nessa obra, ser traída pelo companheiro, é ser traída pelo colonizador. Essa metáfora condensa o que aconteceu com os descendentes afrobrasileiros no decorrer do último século. Para esse entendimento, levamos em contra a estratégia pós-coloniais de interpretação, na qual podemos "vincular as estruturas de uma narrativa às ideias, conceitos e experiências em que ela se apoia" (SAID, 1995, p. $105)$.

Ao ser traída pelo companheiro, que opta pela ótica capitalista do colonizador, Bertoleza não vê outra saída a não ser cometer o suicídio. Mesmo com seu trabalho, sua dedicação e fidelidade, teve seu esforço sucumbido pelos interesses sociais de João Romão. Essa traição é uma metáfora muito importante para entendermos o processo de colonização, no qual o afro-brasileiro trabalhou e construiu a história do país, mas teve seu lugar renegado às margens. Tal lugar reforça uma estratégia do colonizador de silenciamento desses protagonistas da história nacional.

Ademais, outras personagens afro-brasileiras, ao longo da trama nos remetem para a percepção de que a condição do negro na sociedade é justificada pelas teorias científicas, que o inferiorizam por sua formação intelectual, visto que tantos os negros como as negras são descritos em espaços de exclusão ou de trabalho forçado. Esse olhar de revisão também é fundamental para entendermos que a imagem dos afro-brasileiros foi produzida desses lugares de forma proposital para enaltecer as conquistas dos descendentes dos colonizadores brancos.

No espaço do cortiço, há lugar para a figura do malandro carioca, Firmo, o namorado de Rita, que também pode ser associado à identidade do afro-brasileiro. Ele traz outro estereótipo do afro-brasileiro: um capoeirista, forte, mas mulherengo, cachaceiro. Mulato, assim como Rita Baiana ostenta a responsabilidade de corresponder a uma marca afro-brasileira nacional: o sambista.

Portanto, a revisão do olhar afro-brasileiro precisa partir de um lugar crítico de revisão do passado, expondo valores ideológicos que atravessam a formação da identidade nacional. Ora são características aceitas por serem da cultura nacional, ora são rejeitadas por serem de um povo marginalizado. Tal análise nos encaminha a crer que a diversidade racial, identificada na obra de Aluísio Azevedo, é fortemente apresentada de maneira estereotipada e tendenciada pelas teorias vigentes no seu século; carregada de marcas preconceituosas que, infelizmente, convergem para que nos dias 
atuais permaneçam sendo divulgadas pelos meios de comunicação: novelas, filmes, literatura, livros didáticos etc.

\section{CONSIDERAÇÕES FINAIS}

Após a leitura de $O$ cortiço, de Aluísio Azevedo, sabemos que há uma longa coleção de textos que precisam ser relidos pela ótica pós-colonial. Com essa estratégia, abrimos espaço para um olhar contemporâneo, que agrega novas figurações para a identidade afro-brasileira, ao se opor ao discurso padronizado do colonizador (DUARTE, 2010, p. 36). A revisão pós-colonial nos convida a explorarmos as especificidades do texto com o propósito de ampliação desse debate que tanto pode ser feito por textos que trazem as marcas da "literatura negra" (BERND, 1987) como pelas obras que trazem o engajamento e luta pelo direito de uma "literatura afro-brasileira" (DUARTE, 2014).

As estratégias pós-coloniais de interpretação do texto literário são respaldadas por uma disposição ideológica de revertermos os sentidos do senso comum, que insiste em negar a presença do preconceito racial nas representações literárias. Sabemos o quanto o texto literário foge das amarras e travas que uma interpretação ideológica tenta impor. Todavia, reconhecemos que, somente, com estratégias que se voltem para desnudar os signos da colonização conseguiremos reverter a história do preconceito racial no Brasil.

O deslocamento do lugar confortável das interpretações canônicas nos guia por novos roteiros de interpretação literária. Por isso, ressaltamos o método pós-colonial de revisão do passado como uma forma de atualizarmos os sentidos dos textos literários. Assim, ratificamos que, no processo de revisão das representações afro-brasileiras, não podemos "apagar a identidade de um texto", todavia não podemos deixar de reconhecer que seus sentidos não são fixos, pois "o que era, ou parecia ser, certo para uma determinada obra ou autor pode ter se tornado discutível" (SAID, 1995, p. 105).

\section{REFERÊNCIAS}

AZEVEDO, Aluísio. O cortiço. São Paulo: Ática, 1984.

BERND, Zilá. Negritude e Literatura na América Latina. Porto Alegre: Mercado Aberto, 1987.

BHABHA, Homi. O local da cultura. Belo Horizonte: UFMG, 1998.

Volume 17

Número 38 


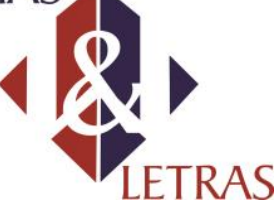

BRASIL. Lei 10.639/2003. Brasília: MEC, 2003. Disponível em: http://www.planalto.gov.br/ccivil_03/leis/2003/L10.639.htm. Acesso em: 20 mai. 2015. DUARTE, E. A. Falas do outro: literatura, gênero, etnicidade. Belo Horizonte: Nandyala. 2010.

DUARTE, E. A. Literatura e afrodescendência no Brasil. Belo Horizonte: Editora UFMG, 2011.

DUARTE, E. A. Literatura afro-brasileira um conceito em construção. Belo Horizonte:

FALE/UFMG, s/p. 2015. Disponível em:

http://www.letras.ufmg.br/literafro/afrodescendenciaseduardo.pdf. Acesso em: 24 abr. 2015.

ECO, Umberto. Lector in fabula. São Paulo: Perspectiva. 2004.

ECO, Umberto. Interpretação e superinterpretação. São Paulo: Martins Fontes, 2005.

GOMES, Carlos Magno Santos. O modelo cultural de leitura. Nonada Letras em

Revista. Porto Alegre, n. 18, p. 167-183, 2012.

GOMES, Carlos Magno. Leitura Literária: o intertexto cultural. RAMALHO, Christina, CARDOSO; Ana Leal; GOMES, Carlos Magno (Orgs). Leituras literárias: mito, gênero e ancestralidades. São Cristóvão: Ed UFS, 2014, p. 105-118.

HALL, Stuart. Da diáspora: identidades e mediações culturais. Belo Horizonte: UFMG, 2003.

SAID, Edward. Cultura e imperialismo. São Paulo: Companhia das Letras, 1995.

Data de recebimento: $31 / 07 / 2017$

Data de aprovação: 23/11/2016 